\title{
Pattern and Prevalence of Psychiatric Comorbidity in Patients with Essential Hypertension in Port Harcourt, Nigeria
}

\author{
Nkporbu Aborlo Kennedy ${ }^{1}$, Stanley Princewill Chukwuemeka ${ }^{1}$, Ohaeri Jude ${ }^{2}$ \\ ${ }^{1}$ Department of Neuropsychiatry, University of Port Harcourt Teaching Hospital, Port Harcourt, Nigeria \\ ${ }^{2}$ Federal Neuropsychiatric Hospital, Enugu, Nigeria
}

Email address:

nakpigi2008@yahoo.com (N. A. Kennedy)

\section{To cite this article:}

Nkporbu Aborlo Kennedy, Stanley Princewill Chukwuemeka, Ohaeri Jude. Pattern and Prevalence of Psychiatric Comorbidity in Patients with Essential Hypertension in Port Harcourt, Nigeria. American Journal of Psychiatry and Neuroscience. Vol. 4, No. 1, 2016 , pp. 5-12. doi: 10.11648/j.ajpn.20160401.12

\begin{abstract}
Essential hypertension, a non communicable disease, is assuming an epidemic dimension, of the nature of a communicable condition. It, predominantly affects the physical, social and psychological well-being of the middle to elderly age group, with the former incidentally contributing over $50 \%$ of Nigeria workforce, hence interfering with the nation's economic well- being. Although few of such studies have been done in this environment, hypertensionhas been variously cited to be commonly associated with psychiatric comorbidity. The aim of this study, therefore, was to determine the pattern and prevalence of psychiatric co-morbidity among subjects with essential hypertension attending the out patient clinic of the University of Port Harcourt Teacing Hospital (UPTH). In this cross-sectional study, following ethical approval from the appropriate committee of the hospital and informed consent from the participants, 360 subjects making up the study group were recruited based on the study's inclusion exclusion criteria, after a Pilot Study (In addition, the hypertensives were screened for HIV infection and also investigated for other chronic medical illnesses). Subjects were further administered with the study's instruments including the socio-demorgraphic questionnaire, GHQ-12 and WHOCIDI. The data were analyzed using the SPSS version 20. Confidence interval was set at $95 \%$ while P - value of less than 0.05 was considered statistically significant. The study found a $64.4 \%(\mathrm{n}=232)$ rate of psychiatric comorbidity among the hypertensive patients with depressive illness the highest with 73(29.4\%). This was followed by GAD with $16.1 \%$, sexual dysfunction $9.0 \%$, mixed anxiety and depression $7.8 \%$, substance abuse $2.3 \%$, dysthymia $0.3 \%$, while panic without agoraphobia and personality disorders $0.9 \%$ each. Severity of hypertension correlated positively with psychiatric comorbidity. The study found that psychiatric comorbidity among the hypertensive patient is common in UPTH. It therefore becomes imperative that the intervention measures for chronic disorders of these natures should include a well planned, elaborate and articulated neuropsychiatric evaluation for an effective and holistic management of these patients.
\end{abstract}

Keywords: Pattern, Prevalence, Psychiatric Comorbidity, Essential Hypertension, UPTH

\section{Introduction}

There is a growing population of persons with essential hypertension worldwide and particularly in Nigeria despite all efforts at increasing education and awareness about the medical condition [1, 2-6, 7, 8-10, 11-19] to the extent of attracting the attention of national and international bodies [20]. WHO estimates that non communicable diseases like hypertension and other heart diseases, stroke, depression and cancers will increase by $60 \%$ by 2020 , and are likely to triple in Nigeria and other sub-Saharan African countries in the next 50 years. According to the World Health Report, non communicable diseases accounted for $22 \%$ of the total deaths in the region in the year 2000; cardiovascular diseases alone accounted for $9.2 \%$ of the total deaths, killing even more than malaria [21]. Indeed, it has already been projected that up to three quarters of the world's hypertensive population will be in economically developing countries by the year 2025 [7]. With increased prevalence rates and the resultant greater economic and health burden, [8-10] Nigeria will feel the impact mostly due to its population size.

Cardiovascular diseases are known to cause a third of all 
deaths in middle-income countries, [21] including Nigeria, with particular predisposition to cardiovascular events like CHD, stroke, which are mainly due to poor control of hypertension. Such cardiovascular events, either alone or with psychiatric comorbidity, will also place a big economic burden on Nigeria since they are expensive to manage [22].

Essential hypertension is a chronic systemic disease and is becoming increasingly associated with psychiatric comorbidity, as high as $30-60 \%[23,24-26,27,28]$. It causes an enormous burden on both the patients and the caregivers [29, 8-10]. Unfortunately, there appears to be a general under recognition or late recognition of and in some cases poor attention to the psychiatric component among clinicians [30$33,34]$ particularly in this environment [68]. This is often accompanied by increased severity of these illnesses, poor management and prognosis with eventual high mortality rates. Late recognition of mental disorders in hypertensive patients is related, among others, with diminished coping capacity at diagnosis [35], failure at primary prevention, poor antihypertensive choice [36-40], impairment in quality of Iife, [41-46, 47, 48-50] greater social burden, overall increases in healthcare costs, [22, 51-52] and also higher mortality. [50] Also, psychological distress and lifestyle variables are equally associated with noncompliance. To further compound the problem is the co-existence of other medical conditions like diabetes and obesity, with either of the medical conditions in this study. Their presence further complicates treatment and worsens compliance [53].

For these reasons, a prompt multidisciplinary approach involving evaluation, counseling, and treatment of mental disorders in hypertensive patients is becoming more important [54]. Therefore, determination of the nature and magnitude of psychiatric comorbidity, the additive effects on psychological well-being and quality of life as well as emphasis on the need for mental health component in the management of this chronic medical conditions form the areas of concern of this study. The motivation to carry out this study derived from the finding that hypertensive diseases constituted a greater percentage of all the referrals from other non-psychiatric units seeking for psychiatric evaluation in the University of Port Harcourt Teaching Hospital (UPTH) [68].

This study was designed to evaluatethe psychiatric morbidity in patients with this medical conditions, and this, no doubt, would be of immense relevance to the practice of consultation liaison psychiatry in the West African subregion, contribute to the corpus of knowledge on chronic medical conditions and aid care/service providers to plan better management strategies that will also accord premium to the psychological component and well-being of these patients. Impairments, disabilities and handicaps from chronic conditions may thus be limited and patients' dignity and functional capacity enhanced.

\section{Aim}

The aim of this study, therefore, was to determine the pattern and prevalence of psychiatric co-morbidity in subjects with essential hypertension and also to determine the relationship between the severity of hypertension and psychiatric comorbidity.

\section{Methodology}

In this comparative cross-sectional study, following ethical approval from the appropriate committee of the hospital and informed consent from the participants, 360 subjects making up the study group were recruited based on the study's inclusion and exclusion criteria, after a Pilot Study for both groups. In addition, the hypertensives were screened for HIV infection. Subjects were further administered with the study's instruments including the socio-demorgraphic questionnaire, GHQ-12 and WHO CIDI. The data were analyzed using the SPSS version 20 statistical package. Confidence interval was set at $95 \%$ while $\mathrm{P}$-value of less than 0.05 was considered statistically significant.

\section{Study Design}

This was a cross sectional study. Those considered suitable for the study were patients who had been seen and diagnosed as having Essential Hypertension by the consultant family physician as Study group and those who have been screened and confirmed to be seropositive of retroviral disease, as Control by both the consultant physician and hematologist. The hypertensive patients have all had basic investigations: $i$. e. full blood count, blood urea and electrolytes estimation and urinalysis, in most cases. In addition, some had electrocardiograms (E. C. G), chest x-rays, serum cholesterol, uric acid, creatinine and creatinine clearance estimations. Investigation results were all recorded in the case notes.

Hypertensive patients with primary myocardial or valvular disease, in cardiac failure, renal failure or who had a stroke, or coronary heart disease, diabetes, asthma, or other chronic illnesses or those found to be acutely ill were excluded. Patients were required to have been diagnosed for at least the past one year and have had at least six months of treatments.

The hypertensive patients were all screened for retroviral disease using the rapid HIV screening kit and those who tested positive were excluded and referred to the virology clinic for further evaluation.

\section{Study Instruments}

The following instruments were used in this study:

1. Sociodemographic/ clinical questionnaire.

2. General Health Questionnaire, version - 12 (GHQ-12).

3. World Health Organization Composite International Diagnostic Interview (WHOCIDI).

\subsection{Sociodemographic/Clinical Questionnaires}

Coded socio demographic and clinical characteristics questionnaires were administered to the patients. The coded numbers were to enable tracking of patients. Information including age, sex, marital status, occupation, and level of 
education, monthly income (monthly salary stipend or profit after transactions), diagnosis, age at onset of illness, durations of illness and treatment, initial reaction to diagnosis, and level of drug compliance, were all requested on the questionnaire.

\subsection{The General Health Questionnaire (GHQ - 12)}

It is a self administered screening instrument, which was designed to detect short-term changes in mental health (Anxiety, depression, somatic symptoms and social dysfunctions) and to screen for psychiatric morbidity [55]. It is aimed at distinguishing between psychological ill health and well-being. It can detect disorders of less than two weeks duration. It focuses on breaks in normal functioning and is concerned with a person's inability to continue with normal healthy functions and the experience of new phenomena of a distressing nature. In this study, the GHQ-12 was scored using the conventional method in which "less so than usual" and "no more than usual" were scored 0 , while "rather more than usual" and "much more than usual" were scored 1 . This method treats the scale as a binominal response as pathological deviations from the normal indicates the presence of the rated item. The expectant resultant loss of information by this method makes it only marginally less efficient. This form of scoring has the advantage of being easy to score in this instrument in the Nigerian setting [55]. Psychiatric morbidity was defined as those scoring 3 or more [55]. It can be completed in less than 3 minutes.

\subsection{Suitability and Validity of the 12-Item General Health Questionnaire (G. H. Q-12)}

Goldberg identified the G. H. Q as the most suitable instrument for the detection of minor psychiatric illness in cross-sectional studies. It has been tested extensively in various cultures and linguistics groups and it generally yields high validity and positive results according to Koeter, who also tested among the Chinese and Munoz. The GHQ has been shown to be a valid instrument for the detection of psychiatric morbidity in both general medical settings and in the community. It has been demonstrated by many studies to have a high correlation coefficient with standardized assessment instruments. Moreover, the sensitivity and specificity of the GHQ regardless of its version has remained high with only slight differences depending on the versions.

\subsection{The Composite International Diagnostic Interview (CIDI)}

The World Health Organization (WHO) first developed the CIDI in 1990. The CIDI (CIDI V2.1) was an expansion of the Diagnostic Interview Schedule (DIS) developed by Lee Robins et al. with the support from the National Institute of Health. The CIDI addressed the problem that the DIS diagnoses are exclusively based on the definitions and criteria of the Diagnostic and Statistical Manual (DSM) of Mental Disorders, while the international standard diagnostic system used is the WHO International Classification of Disease (ICD). Therefore, by including the ICD, it was possible to do cross-national comparative research.

The CIDI Screening Section: The very first section in the WHO CIDI interview is the Screening Section. Methodological research has shown that separating the stem questions from the probe questions in this way dramatically increases the accuracy of diagnostic assessments by reducing the effects of respondent fatigue and unwillingness to disclose on stem question endorsement. All respondents of the CIDI completed the entire screening section, regardless of the diagnostic sections that was decided to administer for the study. This allows comparison across samples and surveys that differ in the exact diagnoses assessed.

\section{Results}

A total of $232(64.4 \%)$ subjects had associated psychiatric comorbidity, while 128 (35.5\%) had no psychiatric diagnosis. Out of the total number with psychiatric comorbidity, 106 (29.4\%) had a depressive illness, comprising 25 (22.9\%) males and $81(77.1 \%)$ females. Generalized anxiety disorder (GAD) was diagnosed in $58(16.2 \%)$ patients, $27(7.5 \%)$ males and $31(8.6 \%)$ females. $32(9.3 \%)$ patients had sexual dysfunction out of which $27(7.5 \%)$ had male erectile dysfunction while $5(1.4 \%)$ had hyposexual dysfunction and was diagnosed all in females. Cases of mixed anxiety and depression were diagnosed in $1(5.8 \%)$, in which males constituted 5 (3.5\%) while females were 16 (7.4\%). Panic disorder without Agoraphobia was reported in $4(1.1 \%)$ respondents with equal sex distribution. Eight (2.3\%) respondents had a diagnosis of substance abuse mainly with alcohol, 7 were males and 1 female, and only 1 female subjects had dysthymia.

It is important to note that $20(5.6 \%)$ patients were diagnosed with more than 1 condition. Erectile dysfunction and substance abuse was diagnosed in I patient, I respondent had GAD, substance abuse and erectile dysfunction, 5 respondents had GAD and hyposexual dysfunction, 6 had GAD and male erectile dysfunction, 2 mixed anxiety and depression, and male erectile dysfunction, 5 had depressive illness and male erectile dysfunction. This accounted for the excess above 590 patients if the total diagnoses are summed up.

Table 1. Pattern and Prevalence of Psychiatry Morbidity in Subjects with Essential Hypertension.

\begin{tabular}{|c|c|c|c|c|}
\hline \multirow{2}{*}{$\mathbf{S} / \mathbf{N}$} & \multirow{2}{*}{ DIAGNOSIS } & \multicolumn{3}{|c|}{ ESSENTIAL HYPERTENSION } \\
\hline & & Freq. & Male & Female \\
\hline 1 & Substance abuse/male erectile dysfunction & $1(0.3 \%)$ & $1(1.7 \%)$ & $0(0.0 \%)$ \\
\hline 2 & Generalize anxiety disorder/substance abuse/male erectile dysfunction & $1(0.3)$ & $1(1.7 \%)$ & $0(0.0 \%)$ \\
\hline 3 & Generalized anxiety disorder & $36(10.0 \%)$ & $17(11.8 \%)$ & $19(8.8 \%)$ \\
\hline 4 & Generalized anxiety disorder with somatic features & $10(2.8 \%)$ & $4(6.8 \%)$ & $6(2.8 \%)$ \\
\hline
\end{tabular}




\begin{tabular}{lllll}
\hline \multirow{2}{*}{ S/N } & DIAGNOSIS & \multicolumn{3}{l}{ ESSENTIAL HYPERTENSION } \\
\cline { 3 - 5 } & & Freq. & Male & Female \\
\hline 5 & Generalized anxiety disorder & $5(1.4 \%)$ & $0(0.0 \%)$ & $5(2.3 \%)$ \\
6 & Generalized anxiety disorder/ male erectile dysfunction & $6(1.7 \%)$ & $6(4.2 \%)$ & $0(0.0 \%)$ \\
7 & Mixed anxiety and depression/ male erectile dysfunction & $2(0.6 \%)$ & $2(3.4 \%)$ & $0(0.0 \%)$ \\
8 & Moderate depression/male erectile dysfunction & $4(1.1 \%)$ & $4(6.8 \%)$ & $0(0.0 \%)$ \\
9 & Mild depression/male erectile dysfunction & $1(0.3 \%)$ & $1(1.7 \%)$ & $0(0.0 \%)$ \\
10 & Male erectile dysfunction & $12(3.3 \%)$ & $12(7.3 \%)$ & $0(0.0 \%)$ \\
11 & Mild depressive disorders & $35(9.7 \%)$ & $5(3.5 \%)$ & $30(13.9 \%)$ \\
12 & Dysthymia & $1(0.3 \%)$ & $0(0.0 \%)$ & $1(0.5 \%)$ \\
13 & Mild depression with anxiety features & $10(2.8 \%)$ & $2(3.4 \%)$ & $8(3.7 \%)$ \\
14 & Mild depression with somatic features & $7(1.9 \%)$ & $1(1.7 \%)$ & $6(2.8 \%)$ \\
15 & Mixed anxiety and depressive disorders & $21(5.8 \%)$ & $5(3.5 \%)$ & $16(7.4 \%)$ \\
16 & Moderate depressive disorders & $36(10.0 \%)$ & $8(3.6 \%)$ & $28(3.0 \%)$ \\
17 & Panic disorder without agoraphobia & $4(1.1 \%)$ & $2(3.4 \%)$ & $2(1.0 \%)$ \\
18 & Severe depression with psychotic features & $8(2.2 \%)$ & $2(3.4 \%)$ & $6(2.8 \%)$ \\
19 & Personality disorders & $5(1.4 \%)$ & $4(6.8 \%)$ & $1(0.5 \%)$ \\
20 & Substance abuse & $6(1.7 \%)$ & $5(3.5 \%)$ & $1(0.5 \%)$ \\
21 & Nil (No diagnosis) & $128(35.5 \%)$ & $57(15.8 \%)$ & $71(19.7 \%)$ \\
& Total & $360(100 \%)$ & $144(39.5)$ & $216(32.9 \%)$ \\
\hline
\end{tabular}

Table 2. Summary of Psychiatry Diagnosis.

\begin{tabular}{lll}
\hline SN & Psychiatric Morbidity Total & Essential Hypertension (\%) \\
\hline 2 & GAD & 16.1 \\
3 & Depressive disorders & 29.4 \\
4 & Sexual Dysfunctions & 9.0 \\
5 & Substance Abuse & 2.3 \\
7 & Mixed Anxiety and Depressive disorders & 7.8 \\
8 & Panic without Agoraphobia & 0.9 \\
9 & Dysthymia & 0.3 \\
11 & Personality Disorders & 0.9 \\
12 & Nil (no psychiatric illness) & 35.5 \\
& Total & $100 \%$ \\
\hline
\end{tabular}

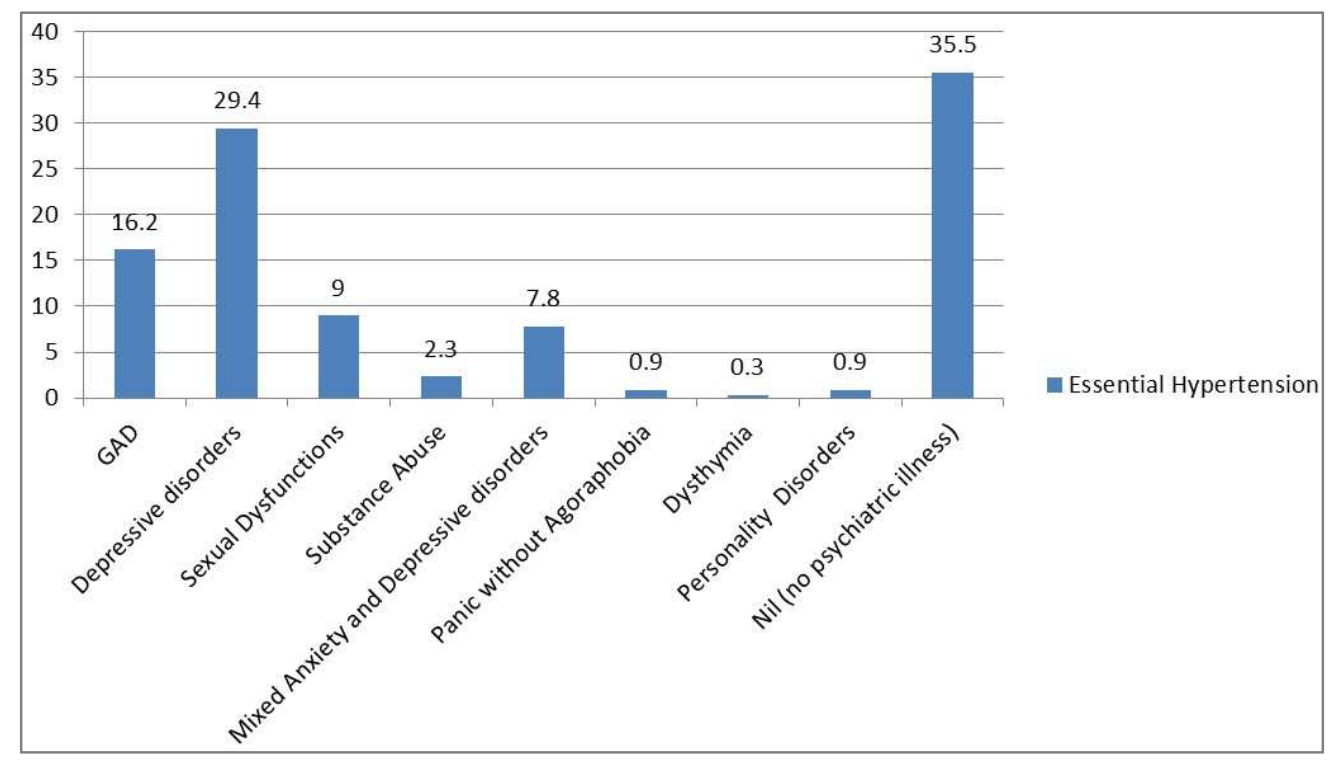

Fig. 1. Bar Chart Showing the Pattern and Prevalence of Psychiatric Morbidity among Persons with Essential Hypertension.

\section{Discussion}

From the results of this study, the prevalence of psychiatric morbidity in the hypertensives was $52.2 \%$. This was slightly higher than results from previous studies [56]. Ohene, in his study in Benin City, found a prevalence of $35 \%$ psychiatric morbidity among persons with essential hypertension [56].
Although these results seem to be far apart, the difference might reflect: one, the increasing environmental stressors and economic hardship, increasing spate of insecurity in Nigeria and particularly in the Niger Delta which has significantly worsened over the last 10 years.

Hypertension alone can present with psychiatric morbidity and this may be aggravated by adverse environmental factors. Adverse environmental factors can in turn predispose 
to essential hypertension and mental illness. Indeed, this relationship describes a sustained vicious circle. Another possible reason for the observed difference was that in the study by Ohene, [56] GHQ-30 was used which is a less sensitive version when compared with GHQ-12 (used in this study). Thirdly, the sample size was smaller, i. e. 40 patients compared with 360 hypertensives used in this study. The higher the sample size, the higher the likelihood of diagnosis of psychiatric morbidity. Furthermore, several studies have suggested that hospital based treatment of hypertensives, tends to be associated with higher neurocitism and levels of psychiatric morbidity, than their counterparts on community based treatment.

Another plausible reason could be the use of some antihypertensive particularly calcium channel blockers and $\alpha$ methyldopa, implicated recently in psychiatry co-morbidity among patients on treatment for hypertension.

Out of the total number with psychiatric illness, $236(65.6 \%)$, depression was significantly the commonest with $39.4 \%$ as against $16 \%$ in Ohene's study [56]. Depression was mostly the mild and moderate types with few cases presenting with psychotic features which were mostly mood congruent. This might also be due to reasons earlier given for overall psychiatric disorders. Hypertension presents with very disabling symptoms which could impair the functional capability of the sufferer. This, coupled with other adverse environmental factors, might predispose the patient to depressive illness.

There was significant predominance of females with depression. This finding, which is consistent with the gender distribution of depression, [57]which may reflect the willingness of the female gender to volunteer information on her health, hence, better health seeking behaviour. Hypertensive disease, which carries the risk of both physical and emotional burden, is likely to affect the mood regulatingcentre of the brain, i. e the limbic system. Mixed anxiety and depression was diagnosed in 21 hypertensive patients, majority of them were females. The preponderance of this mixed affective and neurotic illness in females is in line with findings from previous studies.

The prevalence of generalized anxiety disorder was $16.1 \%$ in this study. Previous study had found $12 \%$. This could possibly be more frequent. The effect of propranolol and benzodiazepins (bromazepam and diazepam) which are commonly used medications in the GOPD, may have been responsible for the relatively low prevalence. Males were $48.2 \%$ and females $51.8 \%$. Again the observed gender bias is in line with existing literature. Earlier studies have suggested that hypertensives were more neurotic, more insecure, more conservative and more tense.

Hypertension and generalized anxiety disorder are somewhat similar illnesses, sharing common pathway - the sympathetic pathway [58]. It is for this reason that medications like beta blockers such as propranolol and some benzodiazepine that act by dampening the activity of the sympathetic pathway, have comparable usefulness in both disease conditions. Another reason to "drive home" the relationship between hypertension and anxiety is that fundamental advances in the understanding of hypertension have coincided with the theories of anxiety states and affective disorders, suggesting catecholemines - particularly known here is noradnenaline[59]. This finds common ground in suggested mechanism for producing increased arterial pressure and neurotic states [59]. This is also consistent with the study by Kidson, [60] who argued that higher neurotic scores of his hypertensive out-patients were due to a "reactive state" occurring in them centrally to other study, [61] which reported the absence of neuroticism among newly hypertensives and suggested that drug treatment could cause the observed neurosis.

However, in this study, the inclusion criteria of one year duration of illness stands to disprove this and it also appears that most of the hypertensives with diagnosis of anxiety were not due to their medication, and most were having one psychosocial stressor or the other that may either be responsible for or worsen the hypertension, anxiety or even both.

Panic disorder was diagnosed in $1.1 \%$ of hypertensive patients in this study. Many workers have consistently established that most of the major deleterious effects of high blood pressure are in the heart, blood vessels, kidneys and brain $[57,59]$. Therefore, with the strong connection between the heart and cardiovascular system, hypertension and the psyche, diagnosis of panic disorder in hypertensive subjects might not be a surprising finding [62, 63]. In fact, other names that have been given to anxiety neurosis (now obsolete) include cardiac neurosis, irritable heart syndrome, soldier's heart, nervous tachycardia, vasomotor neurosis, vasoregulatory asthenia and disordered action of heart, among others. Strikingly, these names mainly further imply the close and strong association between the heart or cardiovascular system and anxiety states [57].

Considering the fact that psychiatric morbidity was most prevalent in the unemployed, elementary, and low income workers, separated and divorced, all baseline psychosocial factors, capable of causing depressive illness, anxiety disorders and other mental illnesses, hypertension is commonly associated with stressful conditions. This is in line with findings from other studies that also showed that some common aetiological factors like stress related situations, issues of job loss and unemployment, prolonged difficulties, people at war front were shown to have hypertension and anxiety [64]. It has been found that stress, which potentially causes anxiety also increases the level of cortisol which in turn causes increased deposition of arterosclerotic deposits in the intima of blood vessels [59]. These deposits gradually narrow the lumen of the vessels. This in turn increases arterial pressure resulting in hypertension [59].

Sexual dysfunction was diagnosed in $9.0 \%$ of hypertensive patients. Of this, $84 \%$ had male erectile dysfunction while $16 \%$ who were all females had hyposexual dysfunction. Hyposexual desire disorder (HSDD) is sexual dysfunction with decreased libido, lack of sexual motivation, and decreased sexual fantasies. Some studies have found 
associations between hypertension and erectile dysfunction in men, while others have implicated effects of some antihypertensive drugs like methyldopa and reserpine, [56, 43] in addition to psychogenic impotence. However, in this study no patient was being treated with reserpine, and of the 27 males with erectile dysfunction, only 3 were on methyldopa.

Another diagnosis that was made among 8 of the hypertensives was substance abuse. More than $80 \%$ of them had alcohol related disorder with the male to female ratio of 7: 1. Although, the gender gap was wide, substance abuse generally is commoner among males than females [57]. There is a bidirectional relationship between substance abuse and hypertension i. e. substance abuse particularly alcohol can cause hypertension while hypertension, on the other hand, can precipitate substance abuse due to frustration [6567]. However, the true relationship still remains difficult to establish in this study. People with hypertension tend to abuse substance mainly to self-medicate their depression or to abate the many anxiety or anxiety like symptoms that characterized hypertension, hence the use of popranolol and diazepam which have anxiolytic effects.

Personality disorder was seen in $5 \%$ of the hypertensive subjects. The concept of type A behaviour pattern (T. A. B. P.), also referred to as Type A personality, which appears fairly well established as a strong correlate of coronary heart disease (CHD), strongly supports a relationship between hypertension and personality disorder. [60] High blood pressure (HBP) is identified as major risk factor to $\mathrm{CHD}$, which is reported to be on the increase in Nigeria. However, the present study found a low rate of personality disorder.

Hypertensive subjects with more than one psychiatric morbidity were seen in this study. $12 \%$ had both GAD and Sexual Dysfunction while $8 \%$ had both major depression and Sexual Dysfunction. This equally agrees with the multifactorial aetiological basis of essential hypertensive with environmental stressors playing as much significant role as genetic factors.

\section{Conclusion}

Psychiatric comorbidity are common with essential hypertension and they appear to be under diagnosed. This invariably affect the management of this medical condition. The presence of psychiatric comorbidity equally adversely affect drug compliance and worsens the prognoses of essential hypertension. It therefore becomes imperative that the intervention measures for most chronic disorders of these natures should include a well-planned, elaborate and articulated neuropsychiatric evaluation component for an effective and holistic management of these patients.

\section{References}

[1] Oviasu VO. The Pattern and Prevalence of Heart Disease in Benin, Nigeria. Nig. Med. J. 1989; 8: 83-85.
[2] WokomaFS, Alasia DD. Blood pressure pattern in Barako: a rural community in Rivers State, Nigeria. The Nigeria Journal, 2011; 11: 813 .

[3] Akpa MR, Alasia DD, Emmen-Chioma PC. An appraisal of hospital based blood pressure control in Port Harcourt, Nigeria. The Nigeria Health Journal.2008; 8: 27-30.

[4] Unachukwu CN, Agomoh DI, Alasia DD. Pattern of noncommunicable diseases among medical admissions in Port Harcourt, Nig. Nig. Journal of Clinical Practice.2008; 11(1): 14-17.

[5] Adefuye BO, Adefuye PO, Oladepo TO, Familoni OB, Olurunga TO. Prevelence of hypertension and other cardiovascular risk factors in an African Urban, sub-urban religious community. Nigerian Medical Practitioner 2009; 55(1-2): 4-8.

[6] Cooper R, Rotimi C, Ataman S, McGee D, Osotimehin B, Kadiri $\mathrm{S}$ et al. The prevalence of hypertension in seven populations of west Africanorigin. Am Public Health 1997; 87(2): 160-8.

[7] Kearney PM, Whelton M, Renoids K, Muntner, P Whenton KP. Global burden of hypertension: analysis of worldwide data Lancet 2005; 365: 217-23.

[8] Murray CJ, Lopez AD. Mortality by cause for eight regions of the world. Global burden of disease. Lancett, 1997; 349: 1269-1276.

[9] Ogbagbon EK, Okesina AB, Biliaminu SA. Prevalence of hypertension and associated variables in paid workers in llorin, Nigeria. Niger J. Clin. Pract. 2008; 11 (4): 342-346.

[10] Lawes CM, Vander Hoorn S, Law MR Eliot P, McMahon S, Rodgers A. Blood pressure and the global burden of disease 2000. part II: estimate of attributable burden J. hypertens 2006; 24: 423-430.

[11] Cappuccio FP, Cook DG, Atkinson RW and Strazzullo P. Prevalence, detection, and management of cardiovascular risk factors in different ethnic groups in south London.Heart1997; 78 (6): 555-63.

[12] Cooper R, Rotimi C, Ataman S, McGee D, Osotimehin B, Kadiri S, et al. The prevalence of hypertension in seven populations of west Africanorigin. Am Public Health.1997; 87 (2): $160-8$.

[13] Adedoyin RA, Mbada CE, Balogun MO, Martins T, Adabayo RA, Akintomide A. Prevalence and pattern of hypertension in a semi-urban community in Nigeria Eur. J. Cardiovasco prev. Rehab., 2008; 15(6): 683.687.

[14] Cappuccio FP, Micah FB, Emmeth L, Kerry SM. Prevalence, detection, management and control of hypertension in Ashanti, West Africa. Hypertens, 2004; 43: 10-17.

[15] Cappuccio FP, Cook DG, Atkinson RW, Stuzzullo P. Prevalence, detection, management of cardiovascular risk factors in different ethinic groups in South Africa. J Health, 1997; 78: 555-563.

[16] Lawoyin TO, Azuzu MC, Kaufman J, Rotimi C, Oweaje E, Johnson L, Cooper R. Prevalence of cardiovascular risk factors in an African, urban inner city community. West Afr. Med 2002; 21: 208-211. 
[17] Chamontin B, Poggi L, Lang T, Menard J, Chevalier H, GalloisH, Cremier O. Prevalence, treatment and control of hypertension in the French population: data from a survey on high blood pressure in general practice, 1994. Am J Hypertens 1998; 11: 759-62.

[18] Wolf-Maier K, Cooper RS, Banegas JR, Giampaoli S, Hense HW, Joffres NM, Kastarinen M, Poulter N, Primatesta P, Rodriguez-Artalejo F, Steg-mayr B, Thamm M, Tuomilehto J, Vanuzzo D, Vescio F. Hypertension, prevalence and blood pressure levels in 6 European countries, Canada, and the United States. JAMA 2003; 89: 2363-9.

[19] Hajjar I, Kotchen TA. Trends in prevalence, awareness, treatment, and control of hypertension in the United States, 1988-2000.JAMA 2003; 290: 199-206.

[20] Health Reform Foundation of Nigeria (HERFON) (2009, August) 'Impact challenges and long-term, implications of antiretroviral therapy programme in Nigeria'.

[21] WHO (2002).The world Health Report: reducing risks, promoting healthy life. Geneva: World Health Organization, (Cited 2008 March). Available from: URL en. Pdf.

[22] Rice D, Kelman S, Miller L. The economic burden of mental illness. Hosp Community Psychiatry.1992; 43: .1227-32.

[23] Arodime EB, IkeSO, Nwokedinke SC. Case fatality among hypertensive-related admission in Enugu, Nig. Nig Journal of Clinical Practice, 2009: 12(2): 153-156.

[24] Goldney RD, Phillips PJ, Fisher LJ, Wilson DH. Diabetes, depression, and quality of life - a population study. Diabetes Care 2004; 27: 1066-70.

[25] Spiegel D, Giese-Davis J. Depression and cancer: mechanisms and dis-ease progression. Biol Psychiatry 2003; 54: 269- 82.

[26] Chobanian AV, Bakris GL, Black HR, Cushman WC, Green LA, IzzoJLJr, Jones DW, Materson BJ, Oparil S, Wright JT Jr, Roccella EJ. Seventhresport of the Joint National committee on Prevention, Detection, Evaluation, and Treatment of High Blood Pressure. Hypertension. 2003; 42: 1206-1252.

[27] Norbert S, Wolfganf T, Johannrs K. Mental Disorders and Hypertension: Factors Associated With Awareness and treatment of Hypertension in the General population of Germany. psychosomatic medicine. 2006; 68: 246- 252.

[28] Erhun WO, Olayiwola, G, AgbaniEO, and Omotoso NS Prevalence of Hypertension in a University Community in South Western Nigeria. African journal of Biomedical Research Ibadan Biomedical Communication Group.2005; Vol. 8: 15-19.

[29] Gwatkin D, Guillot M, Heuveline P. The burden of disease among the global poor. Lancet, 2000; 354: 586-589.

[30] Wenzel U, Roben T, Schwietzer G, Stahl RAK. The treatment of arterial hypertension: a questionnaire survey among doctors in general practice. Deut Med Wochenschr 2001; 126: 1454-9.

[31] Hartley RM, Velez R, Morris RW, Dsouza MF, Heller RF. Confirming the diagnosis of mild hypertension. BMJ 1983; 286: 287-9.

[32] Gupta K. Undertreatment of hypertension: a dozen reasons. Arch Intern Med 2002; 162: 2246-7.
[33] Oliveria SA, Lapuerta P, McCarthy BD, L'ItalienGJ, Berlowitz DR, Asch SM. Physician-related barriers to the effective management of uncontrolled hypertension. Arch Intern Med 2002; 162: 413-20.

[34] Hyman DJ, Pavlik VN. Poor hypertension control: let's stop blaming the patients. Cleve Clin J Med 2002: 69(10): 793-9.

[35] Nichotaon W, Long B. Self-esteem, social support, internalized homophiobia, and coping strategies of men.J Consult ClinPsyohcl.1990; 50-873-6. 53.

[36] Hyman DJ, Pavlik VN. Characteristics of patients with uncontrolled hypertension in the United States. N Engl J Med 2001; 345: 479-86.

[37] DiMatteo MR. Social support and patient adherence to medical treatment: a meta-analysis. Health Psychol 2004; 23: 207-18.

[38] DiMatteo MR, Lepper HS, Croghan TW. Depression is a risk factor for noncompliance with medical treatment-metaanalysis of the effects of anxiety and depression on patient adherence. Arch Intern Med 2000; 160: 2101-7.

[39] Schmitz N, Kruse J. The relationship between mental disorders and medical service utilization in a representative community sample. Soc Psychiatry Psychiatr Epidemiol 2002; 37: 380-6.

[40] Barllett J. Addressing the challenges of adherence .J Acquir immune Defic Synd.2002; 29(Suppl 1) S-SO.

[41] Anderson RB, Testa MA. Symptom Distress Checklists as a Component of Quality-of-Life Measurement Comparing Prompted Reports by Patient and Physician with Concurrent Adverse Event Reports Via the Physician. Drug inf. J. 1994; 28: 89-14.

[42] Testa MA, Simonson DC. Measuring Quality of Life in Hypertensive Patients with Diabetes. Postgrad Med. J.1988; 64: Suppl 3: 50-8.

[43] Testa MA, Hollenberg Anderson RA, Williams GH. Assessment of Quality of Life by Patient and Spouse during Antihypertensive Therapy with Atenolol and Nifedipine Gastrointestinal Therapeutic System Am. J. Hypertens. 1991; 4: 363-73.

[44] Lenderking WR, Gelber RD, Cotton DL, et al. Evaluation of the Quality of Life Associated with Zidovudine Treatment in Asymptomatic Human Immunodeficiency Virus Infection. N Engl. J. Med. 1994; 330: 738-43.

[45] Olusina AK, Ohaeri JU, Subjective quality of life of recently discharged Nigerian Psychiatric patients. Soc Psychiatry Epidemiol 2003; 38 (12): 707-4.

[46] Concepts of Health-Related Quality of Life. In: Patrick D.L, Erickson P. Health Status and Health Policy: Quality of Life in Health Care Evaluation and Resource Allocation. New York: Oxford University Press, 1993; 76-112.

[47] Wenzel U, Roben T, Schwietzer G, Stahl RAK. The treatment of arterial hypertension: a questionnaire survey among doctors in general practice. Deut Med Wochenschr 2001; 126: 1454-9.

[48] Croog SH, Levine S, Tests MA, et al. The Effects of Antihypertensive Therapy on the Quality of Life. N Engl. J Med 1986; 314: 157-64. 
[49] Testa MA. Interpreting Quality-of-Life Clinical Trial: Data for use in the Clinical Practice of Antihypertensive Therapy. J Hypertens Suppl, 1987; 5: S9-S13.

[50] Ii W, Liu L, Purnte JG, Li Y, Jiang X, Jin S, Ma. H, Kong L, Ma L, He X, Ma S, Chen C. Hypertension and Health related quality of life: An epidemiological study in Patients attending hospital clinic in China, Journal of Hypertension.2005; 23(9): 1667-1676.

[51] DuPont R, Rice D, Miller L, Shiraki S, Rowland C, Hanwood H. Economic costs of anxiety. J anxiety. 1996; 2.167-72.

[52] French M, Mauskopf J, League J, Roland E. Estimating the dollar value of health outcomes from drug abuse Interventions. Med Care.1996; 34: 890-910.

[53] Briganti EM, Shaw JE, Chadban SJ, Zimmet PZ, Welborn TA, McNeil JJ, Atkins RC. Untreated hypertension among Australian adults: the 1999-2000 Australian Diabetes, Obesity and Lifestyle Study. Med J Aust 2003; 179: 135-9.

[54] Guidelines Subcommittee. World Health Organization International Society of Hypertension Guideline for the management of hypertension.JHypertens 1999; 17: 151-83.

[55] Peyrot M, Rubin RR. Levels and risks of depression and anxiety symptomatology among diabetic adults. Diabetes Care 1997; 20: 585-90.

[56] Ohene S. Psychiatric Morbidity among Patients with Essential Hypertension Attending Out-Patient Clinics in University of Benin Teaching Hospital. Dissert. WACP. 2003.

[57] Saddocks BI, Saddocks V. Comprehensive Textbook of Psychiatry. 2005; Vol. 1 pg 426-48.

[58] Rostrup M, Kjeldsen SE, EideIK. Awareness of hypertension increases blood pressure and sympathetic responses to cold pressor test. Am J Hypertens. 1990; 3: 912-917.
[59] Oparil S, Zaman MA, Calhoun DA. "Pathogenesis of hypertension”. Ann. Intern. Med. 2003; 139 (9): 761_76.

[60] Kidson MA. Personality and Hypertension J. Psychosom.Res.1973; 17: 35-41.

[61] Cochrane R. Hostility and neuroticism J.Psychosom Res. 1973; 21: 58-62.

[62] Oviasu VO. The pattern of heart disease in Benin, Nigeria. Nig. Med. J. 1983; 3: 192.

[63] Oviasu VO. A study of arterial blood pressure and hypertension in a rural Nigerian community. Afr. J.

[64] Evans D, Charney D. Mood disorders and medical illness a major public health problem. Blot Psychiatry. 2003; 64: 17780 .

[65] JeeSH, He J, Whelton PK, etal. The Effect of Chronic Coffee Drinking on Blood Pressure: A Meta-analysis of Controlled Clinical trials. Hypertension 1999; 33: 647-652.

[66] Lane JD, Pieper CF, Phillips-Bute BG, Bryant JE, Kuhn CM. Caffieine affects cardiovascular and neuroendocrine activation at work and home. Psychosom Med 2002; 64(4): 595. 603.

[67] Mathews JD. Alcohol use, hypertension and coronary heart disease. ClinSciMol Med 1976; 3: 66 IS663S.

[68] Nkporbu A. K, Ugbomah L, Stanley P.C. Pattern and Prevalence of Psychiatric Consultations in Other NonPsychiatric In-patient Facilities in the University of Port Harcourt Teaching Hospital: A 5-YEAR REVIEW. The Nigerian Health Journal.2014; 14; 1, 13-20. 